\title{
What Higher Education Does Right: A Millennium Accounting
}

\section{Philip G. Altbach}

Philip G. Altbach is Monan professor of higher education and director of the Center for International Higher Education at Boston College.

$\mathrm{T}$ he new millennium is upon us. The challenges are daunting-access, expansion, privatization, distance education, technology, and the rest. But let us take a minute to reflect on the successes of the past half century in higher education before we get too depressed about the prospects for the future. The fact is that the higher education is a major force in practically every society, and that on balance academic institutions have met severe challenges with reasonable success. The universities are at the center of today's knowledge-based economies. The postsecondary system has provided access to unprecedented numbers of students. With more than 100 million students enrolled worldwide, higher education has moved from an elite enterprise to a mass phenomenon. These are real accomplishments that are all too often forgotten in the waves of criticism that dominate the popular press in many countries. It may be useful to enumerate some of academe's accomplishments.

\section{Massification and Differentiation}

Most countries have successfully expanded their higher education systems. Massification has been accompanied by a differentiated academic system of institutions with a variety of purposes operating at different levels of quality. The traditional research university is still the pinnacle of most academic systems, but it is no longer the sole model for postsecondary education. Most wealthy and middleincome countries now educate more than 30 percent of the relevant age group in postsecondary education-this is up from under 10 percent or less just two to three decades ago. Many developing countries have doubled access as well. This unique wave of expansion worldwide has added to the knowledge and skills base of society.

\section{Research}

Universities are the key research institutions in most countries. They are the central source for basic research, and as such have provided the underpinning of many of the innovations of modern society. To take just one field, the basic technology that went into the computer and the Internet itself had their origins in universities. Universities are the essential sources of new knowledge in almost all fields. They combine research with teaching in an atmosphere of free inquiry that provides the necessary conditions for productive research.

Social Mobility

Higher education provides unprecedented opportunities for social mobility and improvement in most societies. Bright students from poor backgrounds are able to obtain an education and improve their prospects. Everywhere, higher education increases income levels. Academe has opened up to women practically everywhere, with more women obtaining degrees, and joining the academic profession. Inequalities remain, but progress has been impressive.

\section{Differentiated Funding}

In most countries, academe has found multiple sources of funding. While government in many places remains the key fiscal base for higher education, postsecondary education now obtains money from a much wider array of sources. These include students and their families, philanthropic foundations and individuals, corporations that pay for research and development, consulting fees, patent and other income, and even the sale of sweatshirts. Less dependence on a single source of money has to some extent insulated academe from the vagaries of governmental policies.

\section{Universities are the essential sources of new knowledge in almost all fields.}

\section{Internationalization}

Postsecondary education is more international than at any time since its origins in medieval Europe, when the common language of instruction was Latin. An unprecedented number of students-more than one million-are studying outside the borders of their home countries. There is an international academic labor market, with scholars and researchers routinely crossing borders for jobs. Perhaps most important, knowledge production and dissemination are international in scope, with research teams cooperating across borders and much of scientific communication taking place in English-in many ways the Latin of the $21^{\text {st }}$ century. The curriculum is slowly becoming internationalized as well, and some parts of the world, most notably the European Union, are moving toward common degree structures and mutual recognition of academic qualifications.

\section{Academic Freedom and Freedom of Inquiry}

While there are still restrictions on research and, in some cases, teaching and expression in a number of countries, academic freedom has made remarkable progress in the 
past half century. There is a recognition that for academic institutions to be effective they must be allowed freedom of inquiry.

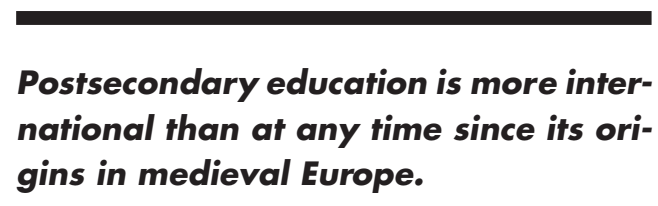

Higher Education and the Civil Society

Universities contribute to the cultural and political life of modern society. They are not only the source of expertise on everything from genetic engineering to classical Greek, but are also the place where controversial issues are debated in an atmosphere of inquiry. Universities are among the few places in modern society where objective analysis takes place. It is not surprising that so many respected experts hold appointments in universities. Academic institutions are central to a civil society, and have, under sometimes difficult circumstances, been able to maintain their independence.

Academic institutions are not perfect, yet they have been remarkably successful during a half century of challenges. Their much criticized conservatism has permitted them to maintain their core values-autonomy, commitment to research and teaching without intellectual restrictions, and the conviction that ideas are important. At the same time, they have adapted to new circumstances. Differentiated academic systems have joined the elite universities, the curriculum has been broadened. Back in the 1960s, British scholar Sir Eric Ashby characterized the United States academic system as "any person, any study." At the beginning of the $21^{\text {st }}$ century, much of the world has joined the United States in offering academic diversity to large numbers. This is a considerable accomplishment.

\section{Global On-line Learning: Hope or Hype?}

\section{Lawrence E. Gladieux}

Lawrence E. Gladieux is executive director for policy analysis, the College Board, 1233 20th St. NW, Washington, D.C. 20036, USA.

E-mail: <lgladieux@collegeboard.org>.

A s of fall 1999, less than 7 percent of the world's adult population was estimated to be connected to the Internet. About 50 percent in the United States and Canada and 20 percent in Europe were on-line, while 2 percent or less were estimated to be on-line in Latin America, Asia, the Middle East, and Africa.

Writing anything about information technology and distance learning these days is at risk of being outdated before anyone can read it, and no doubt the on-line population has already surpassed the above estimates. (The numbers of people on-line by region are available from Lua, Ltd., Dublin [http://www,nua.ie/surveys/how_many_online/ index.html].) But they remind us that the technological infrastructure that some of us take for granted is just not there for much of the world. Within the United States, the Internet revolution seems to be creating a "digital divide" between information haves and have-nots, which is liable to worsen disparities between rich and poor in our society. On an international level, the digital divide may be more like a digital chasm, leaving Third World countries and regions even further behind in the global economy.
Cisco Systems CEO John Chambers has identified education as "the next big killer application for the Internet" (quoted in Thomas L. Friedman, "Next It's Education," New York Times, November 17, 1999). However, sorting out the hype from the reality in today's surging market for the electronic delivery of education is a challenge. The language used today to promote technologydelivered instruction-convenient, self-paced, individualized and interactive, faster and cheaper, flexible as to time and place-echoes that of a string of fads and movements in the United States throughout the 20th century. Thomas Edison speculated early in the century that motion pictures would replace textbooks as the principal medium of instruction. The radio revolution sparked a drive to hook up rural areas to state universities and allow course taking over airwaves. Forty years ago many heralded instructional television as the salvation of the American classroom. Video, satellite, and cable communications followed.

In each case technology enhanced and expanded learning opportunities for people who might not otherwise have had them. But history suggests that the impact of cuttingedge technologies consistently fell far short of the claims made by their proponents.

Now the sensational new phenomenon is on-line learning. The "virtual university" has arrived, and management pundit Peter Drucker has predicted that the residential university campus will be defunct within 30 years. A more likely scenario is that we will spend the next 30 years debating and experimenting with various hybrids of traditional, face-to-face, and technology-mediated learn- 